\title{
La Proteína y El Adulto Mayor ${ }^{1}$
}

\author{
Amanda L. Ford y Wendy J. Dahl
}

La proteína es un nutriente que provee energía a nuestro cuerpo y está involucrado en muchas funciones vitales como el reparo, mantenimiento y buen funcionamiento del sistema inmunológico. Es un componente estructural y funcional en todas las células de nuestro cuerpo, incluyendo enzimas y muchas hormones.

La proteína está compuesta de aminoácidos que provienen tanto de la síntesis en nuestro cuerpo como del consumo en la dieta. Existen 20 aminoácidos. Los aminoácidos esenciales son aquellos requeridos en nuestra dieta. Debemos obtenerlos por medio de la dieta ya que nuestro cuerpo no puede producirlos en cantidades suficientes. Los aminoácidos no esenciales pueden ser producidos por nuestro cuerpo en cantidades suficientes. Durante momentos de estrés, lesiones y traumas, algunos de estos aminoácidos no esenciales pueden volverse esenciales porque nuestro cuerpo ya no puede producirlo en las cantidades necesarias. En estas situaciones de estrés, debemos obtener estos aminoácidos, llamados "condicionalmente esenciales," de nuestros alimentos.

\section{Consumo de proteína y el adulto mayor}

Muchos adultos mayores no consumen la cantidad suficiente de proteína para cumplir con la recomendación actual (Berner et al. 2013). Además, la recomendación de ingesta de proteína actual es menor que la cantidad que se cree necesaria para mantener los músculos y la fuerza a medida que envejecemos (Baum, Kim, and Wolfe 2016).
El envejecimiento está asociado con una disminución de masa muscular y un aumento de grasa corporal. La pérdida de músculo y fuerza a medida que envejecemos se conoce como sarcopenia y puede causar discapacidad, caídas y hospitalización (Dhillon and Hasni 2017). Los adultos mayores que consumen más proteínas en la dieta con el tiempo pierden menos músculo que aquellos que consumen cantidades más bajas de proteína (Baum, Kim, and Wolfe 2016). La ingesta óptima de proteínas puede ayudar a mantener el músculo y potencialmente desarrollar más, especialmente cuando se combina con el ejercicio.

El requerimiento de proteína para adultos mayores aumentan durante lesiones, enfermedades y cirugía (Bauer and Diekmann 2015). Se sugieren dietas con mayor contenido de proteína para los adultos mayores con riesgo nutricional debido a la pérdida de peso involuntaria.

\section{¿Cuánta proteína necesitan los adultos mayores?}

La recomendación de ingesta diaria (RDA, por sus siglas en ingles) de proteína, propuesta para satisfacer las necesidades de la mayoría de adultos sanos, es 0.8 gramos (g) por kilogramo $(\mathrm{kg})(1 \mathrm{~kg}=2.2$ libras $)$ de peso corporal (IOM 2005). Esto equivale a alrededor de $55 \mathrm{~g}$ de proteína para un adulto de 150 libras. La recomendación de ingesta diaria está establecida para satisfacer las necesidades de la mayoría de personas sanas. Actualmente, la recomendación de ingesta diaria de proteínas es la misma para todos los adultos sanos mayores de 19 años independientemente de

2. Este documento, FSHN18-5, es uno de una serie de publicaciones del Food Science and Human Nutrition, UF/IFAS Extensión. Fecha de primera

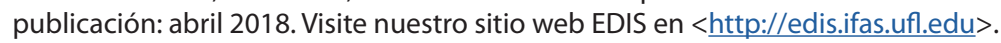

2. Amanda L. Ford, graduate student; and Wendy J. Dahl, associate professor; Food Science and Human Nutrition Department; Gainesville, FL 32611.

The Institute of Food and Agricultural Sciences (IFAS) is an Equal Opportunity Institution authorized to provide research, educational information and other services only to individuals and institutions that function with non-discrimination with respect to race, creed, color, religion, age, disability, sex, sexual orientation, marital status, national origin, political opinions or affiliations. For more information on obtaining other UF/IFAS Extension publications, contact your county's UF/IFAS Extension office. 
los cambios fisiológicos y metabólicos que ocurren con el aumento de edad. Se ha sugerido que se necesita una mayor recomendación de proteínas, más de $1.2 \mathrm{~g}$ por kg para los adultos mayores (Baum, Kim, and Wolfe 2016). Siguiendo esta recomendación más alta, un adulto de $150 \mathrm{lb}$ necesitaría consumir al menos $82 \mathrm{~g}$ de proteína por día.

Para los adultos mayores que tienen sobrepeso, disminuir el consumo de azúcares añadidos y grasa les ayudará a mantener las calorías bajo control cuando aumentan el consumo de proteínas. Aunque la pérdida de peso en adultos mayores obesos presenta riesgo debido a la pérdida de masa muscular, consumir $1.2 \mathrm{~g}$ de proteína por $\mathrm{kg}$ de peso corporal puede mejorar la función en comparación con aquellos que consumen solo $0.8 \mathrm{~g}$ de proteína por $\mathrm{kg}$ de peso corporal (Porter Starr et al. 2016). Los adultos mayores que eligen una dieta de pérdida de peso con mayor proteína pierden menos músculo y más grasa (Kim et al. 2016).

El consumo adecuado de proteínas se puede lograr mediante el consumo de una variedad de alimentos que contienen proteínas. En general, los alimentos de origen animal son más ricos en proteínas y son digeridos fácilmente. Los alimentos de origen vegetal, como las legumbres y los granos (por ejemplo, el trigo), también contienen cantidades significativas de proteínas, aunque en cantidades menores por porción que los productos de origen animal.

Cuando se seleccionan alimentos con proteínas, las recomendaciones sugieren (USDA 2015):

- elegir carnes y aves magras o bajas en grasa;

- consumir al menos 8 oz-equivalentes de pescado cada semana;

- elegir nueces y semillas (nota: $1 / 2 \mathrm{oz}$ de nueces cuenta como $1 \mathrm{oz}$ de un alimento de proteína);

- limitar la ingesta de carnes procesadas (fiambres, embutidos, salchichas); y

- explorar alimentos proteínicos vegetarianos, por ejemplo, legumbres.

El USDA MiPlato brinda orientación sobre las porciones recomendadas de alimentos con proteínas. (Ver https:// www.choosemyplate.gov/protein-foods.) La Tabla 1 enumera el contenido de proteína de algunos alimentos comunes.
Tabla 1. Contenido de proteína de alimentos comunes (USDA 2015).

\begin{tabular}{|l|c|}
\hline \multicolumn{1}{|c|}{ COMIDA } & $\begin{array}{c}\text { Proteina } \\
\text { (g) }\end{array}$ \\
\hline Pollo, pechuga, sin piel, a la parrilla, cocinado (3 oz) & 26 \\
\hline $\begin{array}{l}\text { Carne de res, filete de lomo, a la plancha, cocinado (3 } \\
\text { oz) }\end{array}$ & 26 \\
\hline Salmón, salmón rojo, cocinado (3 oz) & 23 \\
\hline hamburguesa vegetariana (1 hamburguesa ) & 9 \\
\hline Frijoles, negros (1/2 taza) & 8 \\
\hline Leche, reducida en grasa 2\% (1 taza) & 9 \\
\hline Queso Suizo (1 oz) & 8 \\
\hline Queso Mozzarella (1 oz) & 6 \\
\hline Yogurt, natural, leche baja en grasa (6 oz) & 9 \\
\hline Yogurt, Griego, natural, bajo en grasa (5 oz) & 15 \\
\hline Huevo, entero, grande, cocinado duro (1) & 6 \\
\hline
\end{tabular}

$\mathbf{g}=$ gramo, $\mathbf{o z}=$ onza

\section{Alimentos de conveniencia con alto contenido proteico}

Las empresas de alimentos han respondido al interés y la demanda de los consumidores al ofrecer productos que se venden y comercializan como "altos en proteínas". Los productos de alto contenido proteínico son comúnmente comercializados para los adultos mayores (por ejemplo, Ensure ${ }^{\circledR}$ Alto en Proteína, BOOST ${ }^{\circledR}$ Alto en Proteína, Special $\mathrm{K}^{\circledR}$ Cereal de Proteína y una variedad de barras de proteína). Aunque estos alimentos de conveniencia proporcionan una fuente de proteínas, también puede cumplir con su requerimiento de proteínas al elegir alimentos menos procesados como carne, pollo, pescado, productos lácteos y legumbres.

\section{Resumen}

Los adultos mayores corren el riesgo de disminuir la masa muscular magra y por lo tanto la fuerza muscular, y es posible que no consuman la proteína adecuada. Los adultos mayores pueden beneficiarse de una mayor cantidad de proteínas para ayudar a mantener su peso, reducir la pérdida de masa muscular y mantener la salud en general. Elegir alimentos con mayor contenido de proteínas en cada comida ayudará a garantizar que se satisfagan las necesidades de proteínas.

\section{Aprenda Más}

El agente de ciencias de la familia y el consumidor (FCS) en la oficina de extensión de UF/IFAS en su condado puede tener más información escrita acerca de alimentos y nutrición, y además puede tener clases para que 
usted asista. Un dietista registrado (RD) pueden también proveerle información confiable. Es importante hablar con su proveedor de cuidado de la salud antes de realizar cambios en su dieta.

\section{References}

Bauer, J. M., and R. Diekmann. 2015. "Protein and Older Persons." Clin Geriatr Med 31(3):327-38. doi: 10.1016/j. cger.2015.04.002.

Baum, J. I., I. Y. Kim, and R. R. Wolfe. 2016. “Protein Consumption and the Elderly: What Is the Optimal Level of Intake?" Nutrients 8(6). doi: 10.3390/nu8060359.

Berner, L. A., G. Becker, M. Wise, and J. Doi. 2013. "Characterization of dietary protein among older adults in the United States: amount, animal sources, and meal patterns." J Acad Nutr Diet 113 (6):809-15. doi: 10.1016/j. jand.2013.01.014.

Dhillon, R. J., and S. Hasni. 2017. "Pathogenesis and Management of Sarcopenia." Clin Geriatr Med 33(1):17-26. doi: 10.1016/j.cger.2016.08.002.

Kim, J. E., L. E. O’Connor, L. P. Sands, M. B. Slebodnik, and W. W. Campbell. 2016. "Effects of dietary protein intake on body composition changes after weight loss in older adults: a systematic review and meta-analysis." Nutr Rev 74(3):210-24. doi: 10.1093/nutrit/nuv065.

Porter Starr, K. N., C. F. Pieper, M. C. Orenduff, S. R. McDonald, L. B. McClure, R. Zhou, M. E. Payne, and C. W. Bales. 2016. "Improved Function With Enhanced Protein Intake per Meal: A Pilot Study of Weight Reduction in Frail, Obese Older Adults." J Gerontol A Biol Sci Med Sci 71(10):1369-75. doi: 10.1093/gerona/glv210.

U.S. Department of Health and Human Services and U.S. Department of Agriculture. 2015. "2015-2020 Dietary Guidelines for Americans. 8th Edition." http://health.gov/ dietaryguidelines/2015/guidelines/. 